\title{
Chương trình quốc tế ISME thông báo
}

ISME@NEU

March 19, 2012

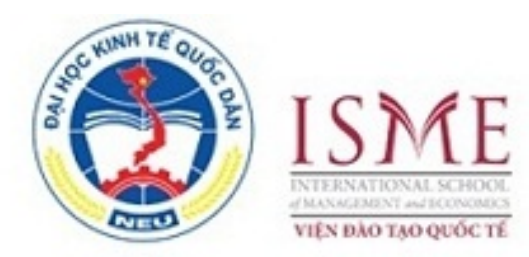

http://neufie.edu.vn/Desktop.aspx/Thong-bao-trang-chu/VN-News/20120319-

Thong_bao_ve_buoi_trao_doi_cua_TS_Vuong_Quan_Hoang_voi_SV_IBDUWE_va_doan_NCS_den_tu_Dai_Loan/ 
NGĀY HŌI THŌNG TIN OPEN DAY

CHUONG TRINH CỬ NHÂN QUỐC TẾ IBD@NEU 23/12/2018 tại ĐHKTQD

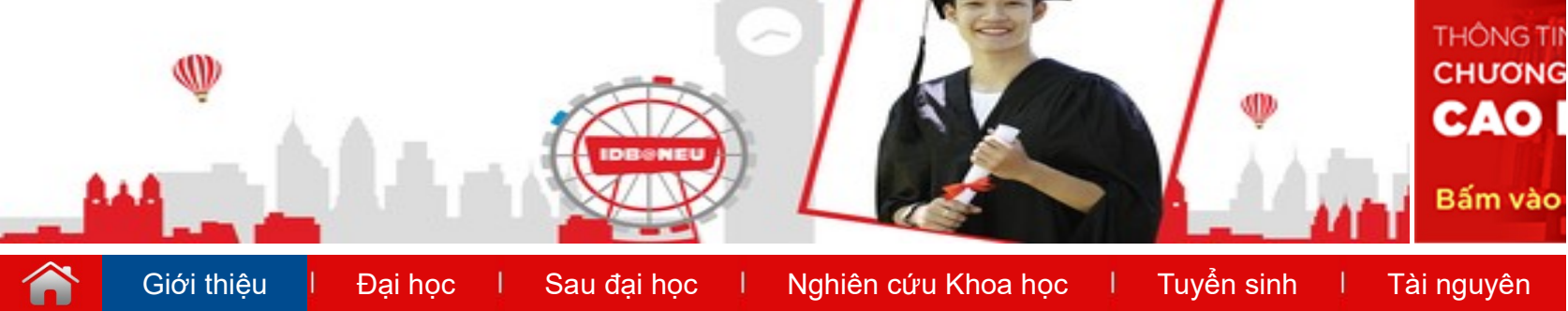

Lời chào mừng | Giới thiệu về Viện ĐTQT | Cơ cấu tổ chức \& đội ngũ cán bộ | Giới thiệu về Trường ĐHKTQD

\section{- THÔNG BÁO}

Thông báo về buổi trao đổi của TS Vương Quân Hoàng với SV IBD-UWE và đoàn NCS đến từ Đài Loan

Nhân dịp đoàn NCS đến từ trường ĐHTH Ling Tung, Đài Loan sang thăm và giao lưu với cán bộ giáo viên và sinh viên Viện ĐTQT, Viện tổ chức buổi gặp gỡ với đoàn kết hợp trao đổi khoa học như sau:

- Diễn giả: TS. Vương Quân Hoàng, chuyên gia phân tích kinh tế và kinh doanh

- Chủ đề: Vietnam's transition economy- possibility of renewed reform \& investment opportunities

- Thời gian: 8.30-10.00 ngày thứ ba, 20/3/2012

- Địa điểm: giảng đường D2, phòng 502.

- Đối tượng: SV chương trình UWE (bắt buộc) và SV IBD khác.

Kính mời các thầy cô giáo cùng các em SV quan tâm đến tham dự.

Vài nét về TS Vương Quân Hoàng:

TS Vương Quân Hoàng lấy bằng tiến sỹ tại ĐHTH Brussels, Vương quốc Bỉ năm 2004. Hiện TS Hoàng đang làm việc cho Khoa Tài chính, Trung tâm Emile Bernheim (ĐHTH Brussels) và Trung tâm Đổi mới và Sáng tạoIndochina thuộc CCI U.S (ĐHTH Boise State, Mỹ).

TS. Vương Quân Hoàng đã xuất bản nhiều cuốn sách gây được sự chú ý như Văn minh làm giàu và nguồn gốc của cải (NXB Chính trị quốc gia- Sự thật), Financial markets in Vietnam's transition economy: Facts, Insights and Implications (Saarbrucken: VDM verlag) và rất nhiều bài báo, bài phân tích đăng trên các tạp chí uy tín của thế giới. 


\section{Bài mới:}

* Danh sách thí sinh dự tuyển vào chương trình IBD khóa 15, đợt 1 kỳ mùa Thu 2019

* Tuyển Ban tổ chức We Are Students 2019

* Tuyển Ban tổ chức Dạ hội SAFARI MASQUERADE 2019

* Tuyển Tư vân viên cho Chương trình BBAE năm học 2018-2019

* Danh sách chia Trung đội, Tiểu đội, Xe, Phòng và Lịch nhận quân phục Boot Camp 2018

* Thông báo hoạt động Trải nghiệm quân trường BootCamp 2018

• Tuyển Mentor cho Tuần lễ Trải nghiệm quân trường Boot Camp 2018

\section{Bài đã đăng:}

* Taste of Solvay 2017 - Hà Nội

*Cao học Việt Bỉ: Tổ chức lễ khai giảng Cao học quản lý công Khóa 7

* Thông báo về buổi sơ khảo Cuộc thi "IBD's Got Talent II" trong khuôn khổ Dạ hội Safari Masquerade 2012

* Cao học Việt Bi: Trân trong thông báo và kính mời tham dự seminar "Marketing trong thế giới thay đổi: Những mô hình và thực tiễn mới" ngày 23/3/2012 tại KS. Melia

* Tuyển sinh viên cho chương trình "Peer Tutor Program" (PTP)

» Safari Masquerade 2012 - Buổi chụp hình và quay clip cho các cặp thí sinh dự thi IBD's Got Talents II

» Buổi giao lưu của Giáo sư Ito Tetsuji, Đại học Ibaraki, Nhật Bản

\section{Solvay Brussels school \\ Economics \& Management}

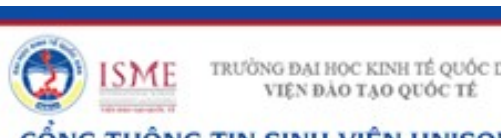

CỔNG THÔNG TIN SINH VIÊN UNISOI

\section{- ĐÓI TÁC}

Liên kêt nhanh

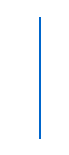

University of

Sunderland

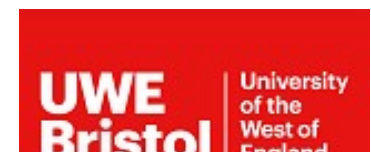

Copyright Trường Đại học Kinh tễ Quốc Dân - Viện Đào tạo Quỗc tễ @ C 2011

Tổng lượt truy cập: 28.139.101 


\section{Tài liệu tham khảo:}

[1] Vương Quân Hoàng. (2007). Văn minh làm giàu \& nguồn gốc của cải. Nxb Chính trị Quốc gia, Hà Nội.

[2] Quan-Hoang Vuong. (2010). Financial markets in Vietnam's transition economy. Saarbrucken, Germany: VDM Verlag. 